DOI: http://dx.doi.org/10.18203/2320-1770.ijrcog20203833

\title{
Impact of condom balloon tamponade on the rate of obstetric hysterectomy: a ten-year study
}

\author{
Archana Roy*, Nalini Mishra, Mamta Sai, Sanjita Pal
}

Department of Obstetrics and Gynecology, Pandit Jawaharlal Nehru Memorial Medical College Raipur, Chhattisgarh, India

Received: 30 June 2020

Accepted: 10 August 2020

*Correspondence:

Dr. Archana Roy,

E-mail: archanaroy756@gmail.com

Copyright: (c) the author(s), publisher and licensee Medip Academy. This is an open-access article distributed under the terms of the Creative Commons Attribution Non-Commercial License, which permits unrestricted non-commercial use, distribution, and reproduction in any medium, provided the original work is properly cited.

\section{ABSTRACT}

Background: The objective of this present study was to assess the efficacy of condom uterine balloon tamponade (CUBT) in averting the obstetric hysterectomy $(\mathrm{OH})$ in cases of major postpartum haemorrhage (PPH) over a period of 10 years.

Methods: A retrospective cohort study from January 2010 to December 2019. A historical cohort was drawn from a group of women who had OH for major PPH between Jan 2010 to December 2014 (Group 1) whereas those from January 2015 to December 2019 were designated as Group 2. Total 305 C-UBT were used in the later period. Women who had $\mathrm{OH}$ at $<28$ weeks were excluded from the study. Primary outcome was to determine the efficacy of C-UBT in averting the risk of $\mathrm{OH}$. Secondary objective was to determine the success rate of C-UBT after five years of use

Results: Total 37463 births occurred from January 2010 to December 2014 and 38808 during January 2015 to December 2019. Cases of $\mathrm{OH}$ were 33 in the first five years period (Group 1) and 20 in the later (Group 2), $\mathrm{p}=<05$, odds ratio $=0.58$ with $95 \%$ CI $0.335-1.019$ favoring C-UBT. After exclusion of rupture uterus and placenta accreta syndrome, $\mathrm{OH}$ for uterine atony alone were $22(66.6 \%)$ for Group 1 and $08(40 \%)$ for Group 2, P=0.01 odds ratio $=0.350$ (95\% CI 0.156-0.788). No OH was done in group 2 for placenta previa. Efficacy of C-UBT was $96 \%$.

Conclusions: C-UBT is very safe, cheap and effective option for averting $\mathrm{OH}$ and associated physical, emotional and psychosocial morbidity.

Keywords: Caesarean delivery, Condom balloon tamponade, Obstetric hysterectomy, Post-partum haemorrhage, Uterine atony, Uterotonics, Vaginal delivery

\section{INTRODUCTION}

In spite of advances in the medical field, the postpartum haemorrhage $(\mathrm{PPH})$ remains the leading direct cause of maternal mortality and morbidity globally and around $99 \%$ of these deaths occurring in low- and middle-income countries (LMICs). ${ }^{1}$

Atony of the uterus is the commonest cause (70-80\%) of $\mathrm{PPH}$ and as soon as PPH is diagnosed, massage of the uterus, emptying of urinary bladder, uterotonic agents along with resuscitative measures are the essential components of medical management. These measures along with injection tranexamic acid, ruling out retained products, assessing coagulation defects and surgical correction of genital trauma (if any) are the first line intervention for the cause directed management approach.

Sometimes the first line measures are not effective or the uterotonics are not available in LMICs which often lack blood bank and surgical facilities also. Some of the uterotonic agents might be contraindicated in the given clinical situation. For such cases of major/severe PPH, it is imperative to use evidence-based guidelines issued by national and renowned world authorities which clearly recommend that while choosing the second line interventions, less invasive methods like uterine balloon tamponade (UBT) should always be used first 
particularly in LMICs. ${ }^{2-10}$ If these methods fail, then more aggressive and invasive interventions including major surgery as a third line intervention may be resorted to save the life of the mother. The obstetric hysterectomy $(\mathrm{OH})$ is the final step of the surgical recourse.

UBT involves insertion of a balloon into the uterine cavity followed by its inflation in order to achieve a tamponade effect and stop bleeding. The first published evidence dates back to 1983 when Goldrath inserted and inflated a Foley's catheter in the uterus to achieve tamponade. There are many variants of UBT, the most commonly used one is a commercially available purpose designed UBT "Bakri balloon $₫ " .{ }^{11-14}$ There is much evidence proving its efficacy. ${ }^{14-17}$ This device however is not a cost-effective option for LMICs.

Amongst the low-cost option of UBT, condom balloon tamponade (C-UBT) device is the most widely used. CUBT was first generated and used in Bangladesh in 2001 by Akhter et al. In India, Shivkar et al prepared indigenous C-UBT named 'SHIVKAR's PACK. ${ }^{18}$ Afterwards many reports established the efficacy of CUBT across India. ${ }^{19-23}$ Use of C-UBT has extended for uncontrolled PPH in hemodynamically unstable patients also. ${ }^{24-29}$ The only RCT comparing Bakri balloon ${ }^{\circledR}$ with C-UBT also reported no significant difference between the two in terms of success. ${ }^{30}$

The advantages of C-UBT are many like being least invasive, cheapest, most rapid, safe, highly effective and need minimum training as well as clinical skill. The resources to assemble it are available in almost every labour room even in LMICs. In spite of all these advantages, the use of UBT is far less than desired in these countries and needs active motivation and training for its implementation.

It has been an observation that UBT plays an important role in averting the need for third line interventions involving major surgery of which the most dreaded ultimate procedure is the obstetric hysterectomy $(\mathrm{OH})$ which itself is associated with additional blood loss in substantial amount besides the need for skilled staff and facility for surgery. These resources are scarce in LMICs. Precise knowledge of the influence of UBT upon $\mathrm{OH}$ will inspire the healthcare providers and policy makers to promote its use and avert the maternal morbidity and mortality associated with it.

Very few studies from developed world have come out with the targeted data showing impact of UBT on decision to surgical intervention. ${ }^{31-34}$ Studies from LMICs are particularly lacking in this regard. In our institute, we have started using C-UBT for last five years with a good success rate in terms of control of PPH but have yet to produce specific data regarding its role in avoiding $\mathrm{OH}$ as the primary outcome. ${ }^{35,36}$
The present study was done with an objective to assess the efficacy of C-UBT in averting the obstetric hysterectomy in cases of major PPH by performing a before-and-after study in order to generate the evidence on the efficacy and safety of this intervention in a tertiary care centre in central India.

\section{METHODS}

Present retrospective cohort study was conducted in the Pt JNM Medical College and Dr BRAM Hospital, Raipur, Chhattisgarh. This is the largest and oldest hospital of the state where about 8000 women give birth annually and also the first teaching hospital to start using $\mathrm{C}$-UBT in a research setting.

This research hypothesis was that the use C-UBT can avert $\mathrm{OH}$ related to $\mathrm{PPH}$ in a significant proportion.

Data for this study was collected for all women who had $\mathrm{OH}$ over a period of last 10 years i.e., from January 2010 to December 2019. As we have started using C-UBT in 2015, it was not possible to have had a concurrent comparison group which was therefore drawn from a historical cohort of women who were managed for major PPH for an equivalent period of time frame of five years preceding the use of C-UBT so that the quality of care received by the pregnant women during this period can be ascertained to be similar with the only difference of use of C-UBT. The group of women who had $\mathrm{OH}$ during the time span from Jan 2010 to December 2014 was designated as PreC-UBT group (Group 1) whereas that from January 2015 to December 2019 was termed as post C-UBT group (Group 2).

As per records, once PPH was diagnosed, the first line treatment of both the group was almost similar and included massage of the uterus and resuscitative measures including fluid administration , catheterization, ruling out retained products in uterus and uterotonic agents in cases of atony and surgical correction of genital trauma in lower genital tract trauma as first line intervention for the cause directed management. All essential investigations were sent and arrangement for blood transfusion was made. Thereafter the management protocol differed in the two groups.

In the Group 1 period (2010-2014), whenever these first line interventions were not effective, women were taken for laparotomy which is the third line intervention because balloon tamponade was not in use at that time and facility for intervention radiology to get uterine artery embolization was also not available. During laparotomy, uterine conserving techniques like compression sutures and de-vascularization were tried first, failing which $\mathrm{OH}$ were resorted to. Similar approach was followed in women undergoing caesarean section.

In the Group 2 period (2015-2019), in cases not responding to initial treatment as above, second line 
intervention in the form of three variants of C-UBT was employed. Those were C G balloon, easy balloon and conventional C-UBT (Figure 3) and in cases of negative tamponade test (failure to arrest haemorrhage after inflating the C-UBT with $500 \mathrm{~mL}$ of saline), women were taken for laparotomy and managed similarly as described above. However, in women undergoing caesarean section, the decision of using C-UBT as a second line intervention or going straight to surgical treatment of $\mathrm{PPH}$ was taken by the operating team and subsequent to conservative surgical measures, $\mathrm{OH}$ was done as a lifesaving option.

Baseline demographic data was then reviewed manually for maternal age, parity, mode of delivery, birth weight of baby, indication of $\mathrm{OH}$, number and types of C-UBT used and blood transfusions. The data so gathered was entered in a proforma prepared for the purpose.

Primary outcome of this study was to determine whether using C-UBT was associated with reduced rate of $\mathrm{OH}$ in cases of major PPH after adjusting for potential confounders.

Our secondary objectives were to determine the success rate of C-UBT after five years of use and whether the use of C-UBT was associated with reduced risk of $\mathrm{OH}$ across various indications.

\section{Inclusion criteria}

Authors included in this study all the women who have undergone emergency obstetric hysterectomy owing to refractory $\mathrm{PPH}$ after having delivered after gestational age of 28 weeks.

\section{Exclusion criteria}

Authors excluded women who had obstetric hysterectomy before 28 weeks of gestation.

\section{Statistical analysis}

The data was entered into excel 2016.sheet and analysed with SPSS version 20. Results were reported as mean, SD or number percentage. Student's unpaired t-test was used for analysis of continuous variables whereas the categorical variables were analysed by Chi square test with $\mathrm{p}=<0.05$ considered as significant. Odds ratio (OR) and corresponding $95 \%$ confidence intervals (95\% CI) were calculated for categorical data.

\section{RESULTS}

During the study period total 76,271 women gave birth in our department, of these 37,463 were in the first five years period from January 2010 to December 201 and 38,808 during January 2015 to December 2019.

Number of women who have undergone $\mathrm{OH}$ were 33 in the first five years period (Group 1) and 20 in the later (Group 2). The women of both the groups were comparable in terms of maternal age, parity, antenatal care booking status, mode of delivery, birth weight and rate of referral (Table 1). The total number of C-UBTs used were 305 in the time span of women belonging to Group 2 versus none in that of Group 1. The difference between the number of $\mathrm{OH}$ in the two groups was significant statistically $(\mathrm{p}=<0.05$, Odds Ratio of hysterectomy with use of C-UBT was 0.58 with $95 \%$ CI 0.335-1.019) (Table 2).

The primary causes of $\mathrm{OH}$ in the two groups are depicted in Figure 1. After exclusion of rupture uterus and placenta accreta syndrome, uterine atony remains the predominating factor (66.6\% for Group 1 and $40 \%$ for Group 2) the difference between the two groups was significant statistically $(\mathrm{p}=0.01$ (HS) odds ratio of having $\mathrm{OH}$ with use of C-UBT (Group 2) was=0.350 (95\% CI 0.156-0.788). No $\mathrm{OH}$ was done in Group 2 for placenta previa. The mode of delivery of baby preceding $\mathrm{OH}$ is also shown in Table 2, significantly more women in Group 1 had to undergo $\mathrm{OH}$ after vaginal birth as compared to Group 2.

The year wise distribution of number of C-UBTs used and that of $\mathrm{OH}$ is shown in Table 3.

Figure 2 shows year wise distribution of $\mathrm{OH}$ due to atonic uterus and number of C-UBTs used in a graphic pattern and shows inverse proportion of the two.

Table 1: Demographic profile of women having undergone emergency obstetric hysterectomy in Group 1 and 2.

\begin{tabular}{|c|c|c|}
\hline Characteristics & $\begin{array}{l}\text { Group } 1(2010-2014) \\
n=33(\text { mean+2SD })\end{array}$ & $\begin{array}{l}\text { Group } 2(2015-2019) \\
(n=20)(\text { mean+2SD })\end{array}$ \\
\hline Age (years) & $29.5 \pm 0.752$ & $30.6 \pm 0.628$ \\
\hline Parity & $2.8 \pm 0.252$ & $2.7 \pm 0.244$ \\
\hline Gestational age at delivery (weeks) & $38.4 \pm 0.33$ & $37.8 \pm 0.511$ \\
\hline Baby weight $(\mathrm{kg})$ & $2.6 \pm 0.127$ & $2.6 \pm 0.094$ \\
\hline Blood transfusion & $3.5 \pm 0.193$ & $4.1 \pm 0.317$ \\
\hline
\end{tabular}




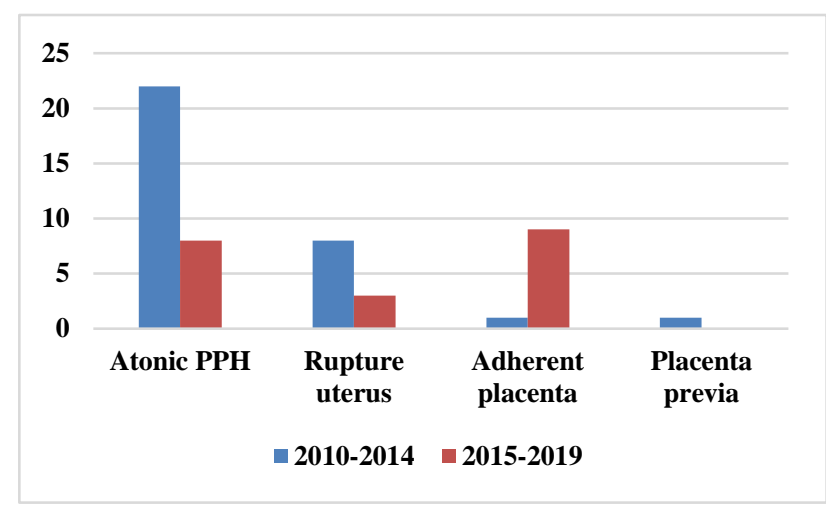

Figure 1: Indications of obstetric hysterectomies before and after C-UBT.

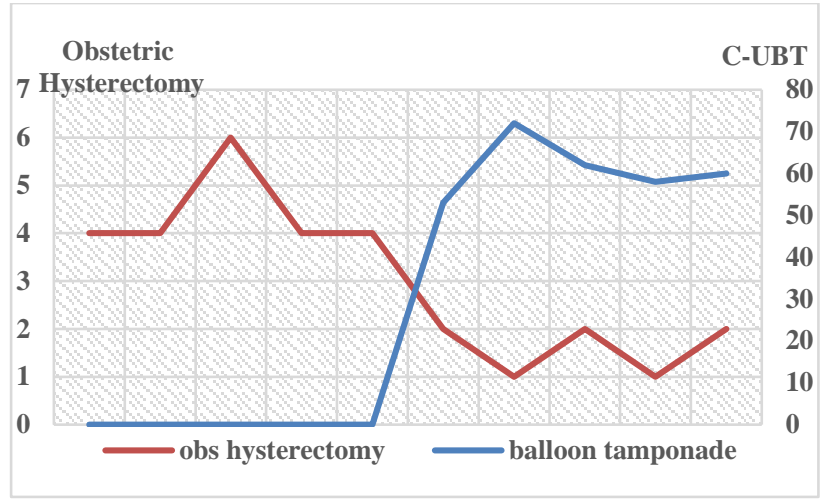

Figure 2: Relation of balloon tamponade and obstetric hysterectomy due to atonic PPH 2010-2019.

Table 2: Comparative data of obstetric hysterectomy (2010-2019) before and after C-UBT.

\begin{tabular}{|c|c|c|c|}
\hline Characteristic & $\begin{array}{l}\text { Group } 1 \\
2010-2014\end{array}$ & $\begin{array}{l}\text { Group } 2 \\
2015-2019\end{array}$ & Effect size P, OR (95\% CI) \\
\hline Deliveries & 37,463 & 38,808 & \\
\hline Balloon tamponade (C-UBT) & 0 & 305 & \\
\hline Obstetric hysterectomies & 33 & 20 & $\begin{array}{l}\mathrm{P}=<0.05,(\mathrm{~S}) \\
\mathrm{OR}=0.584(95 \% \text { CI } 0.335- \\
1.019) \\
\text { Favours use of c-UBT }\end{array}$ \\
\hline $\begin{array}{l}\text { Obstetric hysterectomies due to atonic } \\
\text { PPH (excluding all other causes) }\end{array}$ & 22 & 08 & $\begin{array}{l}\mathrm{P}=0.01(\mathrm{HS}) \\
\mathrm{OR}=0.350 \\
(95 \% \text { CI- } 0.156-0.788) \\
\text { Favours use of c-UBT }\end{array}$ \\
\hline $\begin{array}{l}\text { Mode of delivery preceding obstetric } \\
\text { hysterectomy }\end{array}$ & $\begin{array}{l}\mathrm{n}=33 \\
\text { Vaginal=18 }(55 \%) \\
\mathrm{LSCS}=07 \\
\mathrm{EL}=08\end{array}$ & $\begin{array}{l}\mathrm{n}=20 \\
\text { Vaginal }=07(35 \%) \\
\mathrm{LSCS}=10 \\
\mathrm{EL}=03\end{array}$ & $\begin{array}{l}\mathrm{P}=0.004(\mathrm{HS}) \\
\mathrm{OR}=0.440 \\
(95 \% \text { CI- } 0249-0.778) \\
\text { Favours use of } \mathrm{c}-\mathrm{UBT}\end{array}$ \\
\hline
\end{tabular}

S: significant, HS: Highly significant, OR: Odds ratio, 95\% CI: Confidence interval.

Figure 3 shows the three types of C-UBTs, the frequency with which each of these were used as well as the indications. $\mathrm{C} \mathrm{G}$ balloon was the commonest and used in 162 cases $(53 \%)$ followed by easy balloon in $102(33 \%)$ and conventional C-UBT in 41 women. Out of all $305 \mathrm{C}$ UBTs, majority $(87 \%)$ were used after vaginal delivery versus $13 \%$ women during caesarean section including 2 cases of "sandwich" surgery. In the former group, only $12(4 \%)$ women required third line intervention with 07 managed by conservative surgical measures whereas 05 underwent $\mathrm{OH}$. Remaining $03 \mathrm{OH}$ cases in Group 2 were done for atony not amenable to conservative surgical measures during caesarean section but none of these women had C-UBT attempted prior to hysterectomy.

The success rate of balloon tamponade was $96 \%$ and the commonest indication was atonic PPH $(81 \%)$. There was no complication in Group 2 which could be attributed to C-UBT.

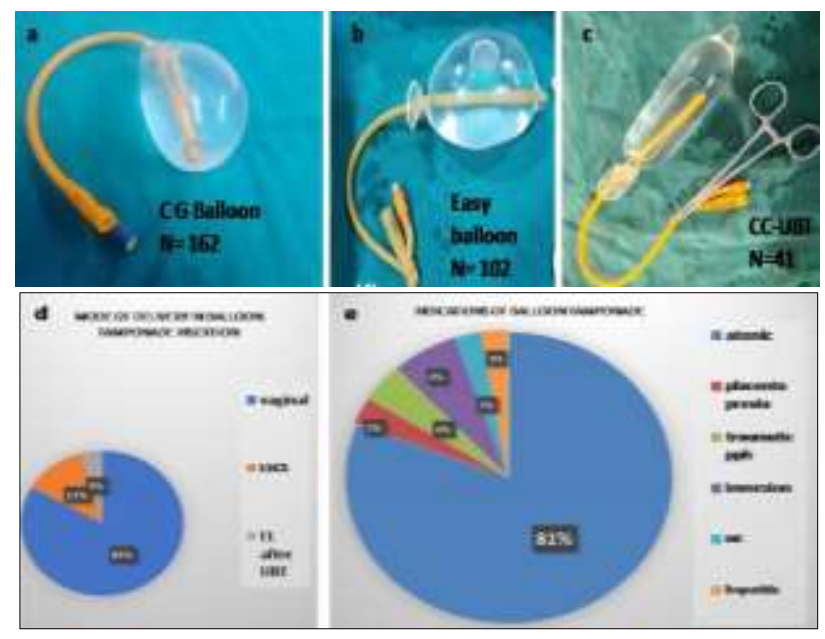

Figure 3: a-c, Types of C-UBT used (a) C G ballooon $\mathrm{n}=162$, (b) Easy balloon $\mathrm{n}=102$, (c) Conventional $\mathrm{C}$ UBT $n=41$. (d) Mode of delivery in all cases of C-UBT use $\mathbf{n = 3 0 5}$, (e) Indications of C-UBT in 305 cases. 
Table 3: Year wise distribution of number of C-UBT and obstetric hysterectomies.

\begin{tabular}{|lllllllllll|}
\hline & Group & $\mathbf{( 2 0 1 0 - 2 0 1 4 )}$ & \multicolumn{7}{c|}{ Group 2 (2015-2019) } \\
\hline Year & 2010 & 2011 & 2012 & 2013 & 2014 & 2015 & 2016 & 2017 & 2018 & 2019 \\
\hline Deliveries & 7203 & 7753 & 7141 & 7599 & 7767 & 7803 & 7759 & 7931 & 7956 & 7359 \\
\hline Balloon tamponade & 0 & 0 & 0 & 0 & 0 & 53 & 72 & 62 & 58 & 60 \\
\hline Obstetric hysterectomy & 07 & 07 & 07 & 06 & 06 & 04 & 02 & 06 & 03 & 05 \\
\hline
\end{tabular}

\section{DISCUSSION}

"A stitch in time saves nine" is a reasonable argument but a more pragmatic approach will always be to avoid it if possible but at the same time ensuring favorable outcome. This becomes even more important in LMICs where necessary infrastructure for surgery is lacking. Another point is that even if the option of surgery is available, why to avail it if avoidable and thereby also avoiding the surgery related morbidity, complications and psychosocial trauma if any radical surgical measure like $\mathrm{OH}$ in these young women had to be resorted to. UBT is one such life-saving intervention which can potentially avert surgery. It is reported to have an overall pooled success rate of $85.9 \%$ according to the most recent metaanalysis published in $2020 .^{37}$ This study results endorse their observations with an efficacy of $96 \%$ and a potential benefit of averting $\mathrm{OH}$ with odds ratio (with use of CUBT) of 0.58 with $95 \%$ CI $0.335-1.019$. This observation is in accordance to others. ${ }^{31-34}$

One important protocol which was followed in our institute was the threshold at which the UBT was used. It was when the woman was well within stage 2 of obstetric haemorrhage according to guidelines by the California maternal quality care collaborative or when the obstetric shock index (pulse rate/ systolic blood pressure) has just crossed 1 with the woman continuing to bleed in spite of first line intervention but before the OSI proceeds to 1.5. ${ }^{35}$ Others have also observed the same fact that it is extremely effective and life-saving especially when placed before the advanced stages of shock. ${ }^{38}$

The most common indication of use in our study was atonic uterus $(81 \%)$. OH due to atony alone were also averted with the use of C-UBT and the difference was significant statistically, $(\mathrm{p}=0.01, \mathrm{HS})$ and $\mathrm{OR}=0.350$ (95\% CI $0.156-0.788)$. C-UBT also averted OH due to bleeding bed of placenta previa where the bleeding bed of placenta responded very well to tamponade effect.

The most preferred variant used in our study was C G Balloon by virtue of having a central drainage lumen and thereby enabling real time assessment of ongoing blood loss. It also enabled us to perform 'Sandwich surgeries' in cases where either UBT or compression suture applied as a lone intervention could have not averted $\mathrm{OH} \cdot{ }^{35,36}$ This fact is in agreement to the study demonstrating UBT combined to surgical treatment of $\mathrm{PPH}$ to be effective strategy during caesarean section with decreased rate of $\mathrm{OH} .{ }^{39}$ The comparative efficacy of $\mathrm{C} \mathrm{G}$ balloon was endorsed by others too. ${ }^{23}$ Though various modifications of C-UBT differ in use including those balancing the hydrostatic pressure with uterine tone the efficacy of each is well established. . $^{37,40}$

To the best of our knowledge, this is the first Indian study demonstrating the specific effect of use of UBT in averting the potential need of $\mathrm{OH}$. This data may motivate clinicians across various level of facilities in LMICs like ours to attempt this cheap, easy to use and prepared at the point of care option before referring or contemplating surgical intervention. This is even more pragmatic in severely anaemic state as a result of uncontrolled haemorrhage superimposed on already anaemic antenatal status. Avoiding $\mathrm{OH}$ also avoids the psychosocial consequences of loss of uterus and fertility in young women.

Limitations of this study was retrospective nature of the study design. However, if it helps to create awareness and enhances use of UBT, it may well be worth. Further studies are needed to reinforce our observation.

\section{CONCLUSION}

There is a definite impact of condom balloon tamponade in decreasing the rate of obstetric hysterectomy in cases of postpartum haemorrhage. This study observation should encourage clinicians across all levels of healthcare facilities to attempt this conservative second line intervention of C-UBT, before proceeding with surgical intervention. C-UBT has the potential to avert the significant physical, emotional and psychosocial morbidity associated with $\mathrm{OH}$. It is very safe and costeffective option for LMICs.

Funding: No funding sources

Conflict of interest: None declared

Ethical approval: The study was approved by the Institutional Ethics Committee

\section{REFERENCES}

1. Global, regional, and national age-sex specific mortality for 282 causes of death in 195 countries and territories, 1980-2017: a systematic analysis for 
the Global Burden of Disease Study 2017. Lancet 2018;392(10159):1736-88.

2. Mavrides E, Allard S, Chandraharan E, Collins P, Green L, Hunt BJ, et al. On behalf of the Royal college of obstetricians and gynaecologists. prevention and management of postpartum haemorrhage. BJOG. 2016;124:e106-e149.

3. Postpartum hemorrhage. Practice Bulletin No. 183. American college of obstetricians and gynecologists. Obstet Gynecol. 2017;130:e168-86.

4. Maternal health division, Ministry of health and family welfare, Government of India, Guidance note on prevention and management of PPH; 2015.

5. WHO recommendations: uterotonics for the prevention of postpartum haemorrhage. Geneva: World Health Organization; 2018.

6. FIGO-SMNH Committee. FIGO GUIDELINES: Prevention and treatment of postpartum hemorrhage in low-resource settings. Int $\mathrm{J}$ Gynecol Obstet. 2012;117:108-18.

7. Georgiou C. A review of current practice in using balloon tamponade technology in the management of postpartum haemorrhage. Hypertens Res Preg. 2014;2:1-10.

8. Doumouchtsis SK, Papageorghiou AT, Arulkumaran S. Systematic review of conservative management of postpartum hemorrhage: what to do when medical treatment fails. Obstet Gynecol Surv. 2007;62:540-7.

9. Brown H, Okeyo S, Mabeya H, Wilkinson J, Schmitt J. The Bakri tamponade balloon as an adjunct treatment for refractory postpartum hemorrhage. Int J Gynaecol Obstet. 2016;135(3):276-80.

10. Aderoba AK, Olagbuji BN, Akintan AL, Oyeneyin OL, Owa OO, Osaikhuwuomwan JA. Condomcatheter tamponade for the treatment of postpartum haemorrhage and factors associated with success: a prospective observational study. BJOG. 2017;124(11):1764-71.

11. Kaya B, Guralp O, Tuten A, Unal O, Celik MO, Dogan A. Which uterine sparing technique should be used for uterine atony during cesarean section? The Bakri balloon or the B-Lynch suture? Arch Gynecol Obstet. 2016;294(3):511-7.

12. Guo Y, Hua R, Bian S, Xie X, Ma J, Cai Y, et al. Intrauterine Bakri balloon and vaginal tamponade combined with abdominal compression for the management of postpartum hemorrhage. J Obstet Gynaecol Can. 2018;40(5):561-5.

13. Kwon HY, Kim YH, Park YW, Kwon JY. Efficacy of Bakri balloon tamponade in massive postpartum hemorrhage: a series of 57 cases. Perinatol. 2016;27(4):236-43.

14. Kadioglu BG, Tanriverdi EC, Aksoy AN. Balloon tamponade in the management of postpartum hemorrhage: three years of experience in a single center. Open J Obstet Gynecol. 2016;6:698-704.

15. Wang D, Xu S, Qiu X. Early usage of Bakri postpartum balloon in the management of postpartum hemorrhage: a large prospective, observational multicenter clinical study in South China. J Perinat Med. 2018;46(6):649-56.

16. Mathur M, Ng QJ, Tagore S. Use of Bakri balloon tamponade (BBT) for conservative management of postpartum haemorrhage: a tertiary referral centre case series. J Obstet Gynaecol. 2018;38(1):66-70.

17. Nagai S, Kobayashi H, Nagata T. Clinical usefulness of Bakri balloon tamponade in the treatment of massive postpartum uterine haemorrhage. Kurume Med J. 2016;62(1-2):17-21.

18. Shivkar KS, Khadilkar SS, Gandhewar M. Pressure balloon therapy in uncontrolled obstetrical haemorrhage. J Obstet Gynecol India. 2003;53:33841.

19. Hasabe R, Gupta Rathode P. Use of condom tamponade to manage massive obstetric hemorrhage at a tertiary center in Rajasthan. The $\mathrm{J}$ Obstet Gynecol India. 2016;66(S1):S88-S93.

20. Ahmad SN, Seth S, Agarwal S, Choudhary S. Evaluating condom catheter balloon tamponade in non-traumatic post-partum hemorrhage resistant to medical management. Int $\mathrm{J}$ Reprod Contracept Obstet Gynecol. 2016;5(6):1874-8.

21. Parpillewar MB, Fusey SS. Intrauterine condom catheter tamponade in the management of atonic postpartum haemorrhage: a case series from a tertiary care centre in Central India. Int J Reprod Contracept Obstet Gynecol. 2017;6(8):3468-72.

22. Santhanam R, Viswanathan RM, Priya V. Condom tamponade in the management of atonic postpartum hemorrhage. Int $\mathrm{J}$ Reprod Contracept Obstet Gynecol. 2018;7(6): 2276-82.

23. Dalia Y, Agrawal M, Sharma A. Various modifications of condom balloon tamponade and their method, efficacy, outcomes in management of atonic postpartum hemorrhage in tertiary care centrea observational study. J Med Sci Clin Res. 2018;6(5):482-9

24. Ranathunga GA. Post partum haemorrhage, severe acute maternal morbidity and the condom catheter uterine tamponade. D A Ranasinghe Oration 2013. Sri Lanka J Obstet Gynaecol. 2013;35(4):100-11.

25. Ramanathan A. Safety of a condom balloon tamponade device for uncontrolled post-partum hemorrhage among facilities in Kenya and Sierra leone. BMC Pregnancy Childbirth. 2018;18(1):168.

26. Anger HA, Dabash R, Durocher J. The effectiveness and safety of introducing condom catheter uterine balloon tamponade for postpartum hemorrhage at secondary level hospitals in Uganda, Egypt and Senegal: a stepped wedge, cluster-randomized trial. BJOG. 2019;126(13):1612-21.

27. Lohano R, Haq G, Kazi S, Sheikh S. Intrauterine balloon tamponade for the control of postpartum haemorrhage. J Pak Med Assoc. 2016;66(1):22-6.

28. Kandeel M, Sanad Z, Ellakwa H, El Halaby A, Rezk M, Saif I. Management of postpartum hemorrhage with intrauterine balloon tamponade using a condom catheter in an Egyptian setting. Int $\mathrm{J}$ Gynaecol Obstet. 2016;135(3):272-5. 
29. Dumont A, Bodin C, Hounkpatin B. Uterine balloon tamponade as an adjunct to misoprostol for the treatment of uncontrolled postpartum haemorrhage: a randomised controlled trial in Benin and Mali. BMJ Open. 2017;7(9):e016590.

30. Darwish AM, Abdallah MM, Shaaban OM,Ali MK, Khalaf M, Sabra AMA. Bakri balloon versus condom-loaded Foley's catheter for treatment of atonic postpartum hemorrhage secondary to vaginal delivery: a randomized controlled trial. J Matern Fetal Neonatal Med. 2018;31(6):747-53.

31. Lo Anderson. St Marie P, Yadav P, Belisle E, Markenson G. The impact of Bakri balloon tamponade on the rate of postpartum hysterectomy for uterine atony. J Matern Fetal Neonatal Med. 2017;30(10):1163-6.

32. Gauchotte E, De La Torre M, Perdriolle- Galet E, Lamy C, Gauchotte G, Morel O. Impact of uterine balloon tamponade on the use of invasive procedures in severe postpartum hemorrhage. Acta Obstet Gynecol Scand. 2017;96(7):877-82.

33. Kong CW. Prognostic factors for the use of intrauterine balloon tamponade for the management of severe PPH. Int $\mathrm{J}$ Gynecol Obstet. 2018;142(1):48-53.

34. Pendleton AA. A qualitative assesment of the impact of a uterine balloon tamponade packeage on decisions regarding the role of emergency hysterectomy in women with uncontrolled postpartum hemorrhage in Kenya and Senegal. BMJ Open. 2016;6:e010083.

35. Mishra N, Gulabani K, Agrawal S, Shrivastava S. Efficacy and feasibility of chhattisgarh balloon and conventional condom balloon tamponade: a 2-year prospective study. J Obstet Gynaecol India. 2019;69, Supplement 2:133-41.

36. Mishra N, Shrivastava C, Agrawal S, Mahilange A, Sai MM, Gulabani K. Easy balloon: the easiest to assemble condom balloon uterine tamponade for primary level of health care centres. J Obstet Gynecol India. 2017;67(5):378-81.

37. Suarez S, Conde-Agudelo A, Borovac-Pinheiro A. Uterine balloon tamponade for the treatment of postpartum hemorrhage: a systematic review and meta-analysis. Am J Obstet Gynecol. 2020;222:293.e1-52.

38. Burke TF, Danso-Bamfo S, Guha M, Oguttu M, Tarimo V, Nelson BD. Shock progression and survival after use of a condom uterine balloon tamponade package in women with uncontrolled postpartum hemorrhage. Int $\mathrm{J}$ Gynecol Obstet. 2017;139(1):34-8.

39. Barinov SV, Zhukovsky YG, Dolgikh VT, Medyannikova IV. Novel combined strategy of obstetric haemorrhage management during caesarean section using intrauterine balloon tamponade. J Maternal-Fetal Neonatal Med. 2017;30(1):29-33.

40. Shivkar's Pack". Available at: Dr. Shivkar Blog. 2011. Dr Shivkar's Blog. 'SHIVKAR's PACK'. N.p., 2011. Web. 27 Aug. 2015.

Cite this article as: Roy A, Mishra N, Sai M, Pal S. Impact of condom balloon tamponade on the rate of obstetric hysterectomy: a ten-year study. Int J Reprod Contracept Obstet Gynecol 2020;9:3638-44. 